\title{
Effects of prebiotic supplementation on the expression of proteins regulating iron absorption in anaemic growing rats
}

\author{
Renata Marciano ${ }^{1}$, Aline Boveto Santamarina ${ }^{1}$, Aline Alves de Santana ${ }^{1}$, Maísa de Lima Correia Silva ${ }^{2}$, \\ Olga Maria Silvério Amancio ${ }^{3}$, Claudia Maria da Penha Oller do Nascimento ${ }^{1}$, Lila Missae Oyama ${ }^{1}$ \\ and Mauro Batista de Morais ${ }^{4_{*}}$ \\ ${ }^{1}$ Department of Physiology, Physiology of Nutrition Discipline, Federal University of São Paulo, Rua Botucatu 862, \\ 2nd floor, 04023-060 São Paulo, Brazil \\ ${ }^{2}$ Department of Pediatrics, Pediatric Gastroenterology Discipline, Federal University of São Paulo, \\ Rua Coronel Lisboa, 826, 04020-000 São Paulo, SP, Brazil \\ ${ }^{3}$ Department of Pediatrics, Research Laboratory of the Nutrology Discipline, Federal University of São Paulo, \\ Rua Botucatu, 703, 04023-062 São Paulo, SP, Brazil \\ ${ }^{4}$ Department of Pediatrics, Federal University of São Paulo, Rua Botucatu, 598, 04023-062 São Paulo, SP, Brazil \\ (Submitted 26 June 2014 - Final revision received 7 November 2014 - Accepted 3 December 2014 - First published online 9 March 2015)
}

\section{Abstract}

Prebiotics may increase intestinal Fe absorption in anaemic growing rats. The present study evaluated the effects of high-performance (HP) inulin and oligofructose on factors that regulate Fe absorption in anaemic rats during the growth phase. Male Wistar rats aged $21 \mathrm{~d}$ of age were fed AIN-93G ration without Fe for 2 weeks to induce Fe-deficiency anaemia. The rats were fed on day 35 a control diet, or a diet with $10 \% \mathrm{HP}$ inulin, or a diet with $10 \%$ oligofructose, without Fe supplementation. The animals were euthanised after 2 weeks, and segments of the duodenum, caecum, colon and liver were removed. The expression levels of proteins in the intestinal segments were assessed using Western blotting. The levels of serum, urine and liver hepcidin and the concentrations of IL-10, IL- 6 and TNF- $\alpha$ in the caecum, colon and liver were measured using the ELISA test. HP inulin increased the expression of the divalent metal transporter 1 protein in the caecum by $162 \%(P=0 \cdot 04)$, and the expression of duodenal cytochrome b reductase in the colon by $136 \%(P=0 \cdot 02)$. Oligofructose decreased the expression of the protein ferroportin in the duodenum $(P=0.02)$, the concentrations of IL-10 $(P=0.044)$, IL-6 (P=0.036) and TNF- $\alpha$ $(P=0.004)$ in the caecum, as well as the level of urinary hepcidin $(P<0.001)$. These results indicate that prebiotics may interfere with the expression of various intestinal proteins and systemic factors involved in the regulation of intestinal Fe absorption in anaemic rats during the growth phase.

\section{Key words: Dietary fibre: Inulin: Intestinal absorption: Iron-deficiency anaemia: Rats}

Fe-deficiency anaemia is the most common and widespread nutritional deficiency in the world, and a public health problem in industrialised and non-industrialised countries with a higher prevalence in women and children ${ }^{(1)}$. Hb concentration has often been used in surveys as a proxy indicator of Fe status under the assumption that anaemia is always associated with Fe deficiency, despite many other possible causes ${ }^{(1)}$.

Mechanisms related to Fe-deficiency anaemia are activated primarily in the duodenum to improve Fe absorption. The large intestine also has been reported to have a capacity for Fe absorption; this area expresses genes that are important for Fe absorption, which are normally expressed in the duodenum, such as duodenal cytochrome b (Dcytb) reductase, divalent metal transporter 1 (DMT1) and ferroportin. Ferric iron is reduced to ferrous iron by Dcytb, an enzyme found on the apical surface of enterocytes and macrophages. DMT1 transports ferrous iron into enterocytes and macrophages. Fe may be stored as ferritin or transferred across the basolateral membrane into the plasma by ferroportin ${ }^{(2)}$. Ferroportin is found in the basolateral membrane where it mediates Fe efflux ${ }^{(3)}$. The importance and function of these genes in the large intestine are not yet clearly understood ${ }^{(4)}$.

Hepcidin controls Fe absorption ${ }^{(3)}$. Hepcidin is a peptide hormone secreted by the liver in response to Fe loading and inflammation. Ferroportin is internalised when hepcidin concentrations are high, and $\mathrm{Fe}$ is trapped in enterocytes,

Abbreviations: Dcytb, duodenal cytochrome b; DMT1, divalent metal transporter 1; HP, high-performance.

*Corresponding author: M. B. de Morais, fax +55 115579 4351, email mbmorais@osite.com.br 
macrophages and hepatocytes, which reduces the efflux of Fe to the circulation system. Ferroportin molecules are exposed to the plasma membrane when hepcidin concentrations are low, which releases $\mathrm{Fe}^{(3,5)}$. Studies have also demonstrated an inverse correlation between hepcidin levels and DMT1, Dcytb and ferroportin levels ${ }^{(2,6)}$. Pro-inflammatory IL-6 increases hepcidin expression ${ }^{(7)}$, which decreases the efflux of Fe to the circulation system.

Prebiotics are used to supplement fermentable dietary fibre, and according to physical-chemical characteristics, they stand out among the nutrients that interact with minerals in the intestine $^{(8)}$. Efforts have been made to study how different nutrients might increase the dietary bioavailability of minerals ${ }^{(9)}$. Inulin, extracted from chicory, and oligofructose are the most-studied prebiotics, and these substances offer new nutritional perspectives ${ }^{(9,10)}$. Inulin and oligofructose affect gastrointestinal functions, and they are fermented in the colon resulting in the production of SCFA, which explains some of the systemic effects of inulin-type fructans ${ }^{(10)}$. Experimental studies in anaemic rats have shown that prebiotics enhance mineral absorption ${ }^{(11-13)}$. A higher regeneration of $\mathrm{Hb}$ and haematocrit concentrations has been shown in inulin- and oligofructose-treated groups during 3 weeks of prebiotic intake in rats with Fe-deficiency anaemia during the growth phase ${ }^{(13)}$. Other studies have demonstrated that inulin and oligofructose increased the expression levels of DMT1, ferroportin and Dcytb genes in the duodenum, caecum and colon ${ }^{(9,14)}$

Most probably, the benefit of inulin and oligofructose in Fe-deficiency anaemia can be exercised beyond the stage of intestinal absorption of $\mathrm{Fe}$, for example at the stage of transfer, storage and recycling of $\mathrm{Fe}$. It remains to be unknown whether inulin and oligofructose could modulate the expression levels of these genes in Fe metabolism ${ }^{(14)}$.

Pro-inflammatory TNF- $\alpha$ and IL- 6 and anti-inflammatory IL-10 increase ferritin protein expression, which increases Fe storage, and IL-10 and IL- 6 increase the acquisition of $\mathrm{Hb}$ by macrophages, which also increases Fe uptake ${ }^{(15)}$, resulting in the decrease of $\mathrm{Fe}$ in blood and anaemia. In contrast, pro-inflammatory IL-6 increases hepcidin expression ${ }^{(7)}$, which reduces the efflux of $\mathrm{Fe}$ to the circulation system. Yasuda et $a l^{(14)}$ demonstrated that inulin and oligofructose decrease the gene expression levels of pro-inflammatory factors in the colon of young anaemic pigs, which influences Fe metabolism.

Therefore, the aim of the present study was to evaluate the effects of high-performance (HP) inulin and oligofructose on the expression levels of DMT1, ferroportin and Dcytb proteins, as well as the inflammatory profile and hepcidin levels in young anaemic rats.

\section{Experimental methods}

\section{Animals and diets}

A total of twenty-one male Wistar rats, aged $21 \mathrm{~d}$ at baseline, were used in the present study. Throughout the study period, the rats received food and deionised water ad libitum through a MilliQ Plus system (Millipore Corporation). All rats were housed in individual metabolism cages made of acrylic and stainless steel (Nalgene Metabolic Cages 650-0100) on a $12 \mathrm{~h}$ light cycle and a temperature of $23 \pm 1^{\circ} \mathrm{C}$. The use of cages allowed the collection of urine.

The animals were fed AIN-93G, as recommended by the American Institute of Nutrition ${ }^{(16)}$, which contained the nutrients needed for proper growth. Fe was not added to the food during the study to induce Fe-deficiency anaemia. There were three spontaneous deaths during this period. The rats were divided into three groups ( $n 7$ per group) in the 5 th week of life ( $36 \mathrm{~d}$ old), according to treatments based on different diet compositions (Table 1). Thus, three groups comprised seven animals each that started to receive one of the following rations, with the respective added prebiotic: rations without $\mathrm{Fe}$ supplementation, but with $103 \cdot 1 \mathrm{~g}$ HP inulin ( $100 \mathrm{~g}$ of dietary fibre; HP inulin group); rations without Fe supplementation, but with $108.7 \mathrm{~g}$ oligofructose ( $100 \mathrm{~g}$ of dietary fibre; oligofructose group); rations without $\mathrm{Fe}$ and dietary fibre supplementation, which was replaced by $100 \mathrm{~g}$ maize starch (control group), as suggested in the literature ${ }^{(17)}$. The amount of HP inulin/oligofructose was subtracted from the total amount of maize starch in the ration. Weight, body length, and $\mathrm{Hb}$ and haematocrit levels were considered with the aim of obtaining uniform groups.

The weight and the length of each animal were measured weekly after the initiation of the experimental diets. Food and water intakes were measured daily during the entire experimental period. The feed efficiency coefficient was calculated, which considered weight gain and food consumption during the entire experimental period using the following formula: weight gain $(\mathrm{g}) /$ food consumption (g) in the same period.

Table 1. American Institute of Nutrition (AIN)-93G ration composition $(50 \mathrm{~g}$ cellulose and $50 \mathrm{~g}$ starch), indicated for rats during the growth phase, replaced by $100 \mathrm{~g}$ high-performance (HP) inulin, oligofructose or maize starch (control diet)

\begin{tabular}{lccc}
\hline Ingredients $(\mathrm{g} / \mathrm{kg})$ & Control & HP inulin & Oligofructose $^{*}$ \\
\hline HP inulin & 0.00 & 103.1 & 0.00 \\
Oligofructose & 0.00 & 0.00 & 108.7 \\
Maize starch† & 579.49 & 476.39 & 475.79 \\
Casein & 200.00 & 200.00 & 200.00 \\
Sucrose & 100.00 & 100.00 & 95.00 \\
Soyabean oil & 70.00 & 70.00 & 70.00 \\
L-Cystine & 3.00 & 3.00 & 3.00 \\
Choline bitartrate & 2.50 & 2.50 & 2.50 \\
tert-Butylhydroquinone & 0.014 & 0.014 & 0.014 \\
Vitamin mixtureł & 10.00 & 10.00 & 10.00 \\
Mineral mix without Fe§ & 35.00 & 35.00 & 35.00 \\
\hline
\end{tabular}

${ }^{*}$ Composition of the following macronutrients in $100 \mathrm{~g}$ of the product: HP inulin - carbohydrate $0 \mathrm{~g}$, protein $0 \mathrm{~g}$, total fat $0 \mathrm{~g}$, dietary fibre $97 \mathrm{~g}$; oligofructose - carbohydrate $5 \mathrm{~g}$, protein $0 \mathrm{~g}$, total fat $0 \mathrm{~g}$, dietary fibre $92 \mathrm{~g}$.

†The fibre portion was replaced by maize starch as suggested by Borel et al. ${ }^{(17)}$.

$\ddagger$ Roche ${ }^{\circledast}$. Composition in mg: nicotinic acid 30 , pantothenate 15 , pyridoxine 6 , thiamin 5 , riboflavin 6 , folic acid 2; composition in $\mu \mathrm{g}$ : vitamin $\mathrm{K} 750$, D-biotin 200, vitamin $B_{12} 25$; composition in IU: vitamin $A$ 4000, vitamin $D_{3} 1000$, vitamin E 75.

$\S$ Roche. Composition in mg: essential minerals - Ca 5000, P 1561, K 3600, S 300, Na 1019, Cl 1571, Mg 507, Zn 30, Mn 10, Cu 6, I 0.2, Mo 0.15, Se 0.15; potentially beneficial minerals (without $\mathrm{Fe}$ ) $-\mathrm{Si} 5$, Cr 1, F 1, Ni 0.5, B 0.5, Li 01 , vo 0.1 . 


\section{Blood sample analysis and experimental procedures}

The rats were anaesthetised using ketamine and xylazine ( 66.6 and $13.3 \mathrm{mg} / \mathrm{kg}$, respectively) weekly after the initiation of the experimental diets, and blood samples were taken from the tail for the determination of $\mathrm{Hb}$ and haematocrit levels. The animals were euthanised via decapitation on day 14 of the experimental diets. Median incisions were performed in the abdominal wall and the peritoneum, and the duodenum was removed $5 \mathrm{~cm}$ from the pylorus. The caecum was isolated by cutting between the ileocaecal valve and the beginning of the proximal colon. The proximal colon (located between the caecum and the median portion of the larger colonic curvature) was removed ${ }^{(18)}$. All of the fresh intestinal sections were weighed on filter paper using an electronic analytical balance (model AB204; Mettler-Toledo) with a sensitivity of $0.0001 \mathrm{~g}$ after excision of the mesentery. The sections were washed with physiological serum to remove the contents in the lumen. The $\mathrm{pH}$ of the caecal contents was also evaluated. The rats were euthanised between 06.00 and 10.00 hours, which is the more active period of intestinal fermentation $^{(19,20)}$. The caecal contents were placed in a beaker immediately after organ extraction, and the $\mathrm{pH}$ was measured using pH-sensitive disposable tapes $\left(\mathrm{PHBIO}^{\circledR}\right.$ Photogenesis Biotecnologia). The liver was excised and weighed while fresh.

Urine collection was performed on the day of euthanasia, and samples were frozen at $-18^{\circ} \mathrm{C}$. Hb levels were determined using the cyanomethaemoglobin and microhaematocrit Wintrobe method ${ }^{(21)}$.

\section{Western blot analysis}

Samples of the duodenum, caecum and proximal colon were homogenised in $1.0 \mathrm{ml}$ of extraction buffer $(100 \mathrm{~mm}$-Trizma, $\mathrm{pH} 7 \cdot 5,10 \mathrm{~mm}$-EDTA, $1 \%$ SDS, $10 \mathrm{~mm}$-sodium pyrophosphate, $100 \mathrm{~mm}$-sodium fluoride, $10 \mathrm{~mm}$-sodium orthovanadate, $2 \mathrm{~mm}$-phenylmethylsulfonyl fluoride and $0.25 \mathrm{mg}$ aprotinin protease inhibitor). The lysates were incubated with $10 \%$ Triton X-100 for $30 \mathrm{~min}$ and centrifuged at $14000 \mathrm{rpm}$ for $30 \mathrm{~min}$ at $4^{\circ} \mathrm{C}$. The supernatant was collected, and protein concentration was determined using a Bradford assay (Bio-Rad), with bovine serum albumin as a standard.

The protein samples were mixed with Laemmli sample buffer, and boiled for $5 \mathrm{~min}$ before loading $100 \mu \mathrm{g}$ protein onto a $10 \%$ SDS-PAGE gel in a Bio-Rad miniature slab gel apparatus. Electrotransfer of the proteins from the gel to a nitrocellulose membrane was performed for $1 \mathrm{~h}$ at $120 \mathrm{~V}$ (constant voltage) using a Bio-Rad miniature semi-dry transfer apparatus. Non-specific protein binding to the nitrocellulose was reduced via a $2 \mathrm{~h}$ pre-incubation in blocking buffer ( $1 \%$ bovine serum albumin, $10 \mathrm{~mm}-$ Tris, $150 \mathrm{~mm}-\mathrm{NaCl}$ and $0.02 \%$ Tween-20). Nitrocellulose membranes were incubated overnight at $4{ }^{\circ} \mathrm{C}$ with antibodies against DMT1, ferroportin and Dcytb (1:1000), or $\alpha$-tubulin (1:1000) (Santa Cruz Biotechnology), which were diluted in blocking buffer combined with $1 \%$ bovine agarose. The membranes were washed for $30 \mathrm{~min}$ in blocking buffer without bovine serum albumin.
The membranes were incubated with a secondary antibody, either anti-goat for ferroportin and Dcytb (1:5000) or antimouse for DMT1 and $\alpha$-tubulin (1:5000) (Santa Cruz Biotechnology). The blots were incubated with a peroxidaseconjugated secondary antibody for $1 \mathrm{~h}$ at $22^{\circ} \mathrm{C}$, processed for enhanced chemiluminescence (Amersham ECL Detection Reagent; GE Healthcare) to visualise the immunoreactive bands, and developed using the Hybond-ECL Nitrocellulose Membrane (Amersham; GE Healthcare). The protein bands were identified according to their migration rates, compared with the rainbow recombinant protein molecular-weight markers, and quantified using densitometry in Scion Image Software (Scion Corporation). Results are expressed as arbitrary units relative to $\alpha$-tubulin.

\section{ELISA}

Quantification of IL-10, IL-6 and TNF- $\alpha$ in the liver, caecum and colon, as well as of hepcidin (USCN Life Science Inc.) in the liver, urine and serum was performed using commercial ELISA kits. Quantitative assessment of TNF- $\alpha$ (DY510), IL-6 (DY506) and IL-10 (DY522) was carried out by ELISA (DuoSet ELISA; R\&D Systems), as described by Rosa et al. ${ }^{(22)}$. For TNF- $\alpha$ and IL-10, sensitivity was found to be $62.5 \mathrm{pg} / \mathrm{ml}$ in the range of $62 \cdot 5-4000 \mathrm{pg} / \mathrm{ml}$, and intra- and inter-assay variabilities were 1.3-9.6 and 4.9-9.5\%, respectively. Assay sensitivity for IL-6 was $125 \mathrm{pg} / \mathrm{ml}$ in the range of $125-8000 \mathrm{pg} / \mathrm{ml}$. Intra-assay variability for IL-6 was $2 \cdot 1-9 \cdot 8 \%$, and its inter-assay variability was 3.3-6.4\%. All samples were run in duplicate, and values are reported as means.

\section{Statistical analysis}

All data are presented as means with their standard errors when numerical variables had a normal distribution, and statistical comparisons of group differences were performed using one-way ANOVA combined with Tukey's test as a post hoc test to compare the control, HP inulin and oligofructose groups. Comparisons were calculated using the Jandel Sigma-Stat program (Systat Software, Inc.). Differences were considered significant at $P<0 \cdot 05$.

\section{Ethical considerations}

The Experimental Research Committee of the Federal University of São Paulo approved all procedures (1342/09) for the care and use of the animals in the present study.

\section{Results}

\section{Growth and food intake}

The control, HP inulin and oligofructose groups exhibited similar weights, lengths, and $\mathrm{Hb}$ and haematocrit levels, and food intake during the experimental period (Table 2). The different diet treatments did not alter food intake or feeding efficiency coefficients. Total feeding efficiency coefficients in the control, HP inulin and oligofructose groups were 0.47 
Table 2. Weight, length (body and tail), $\mathrm{Hb}$, haematocrit levels and food intake during the experimental period in rats from the control, high-performance (HP) inulin and oligofructose groups

(Mean values with their standard errors)*

\begin{tabular}{|c|c|c|c|c|c|c|c|}
\hline & \multicolumn{2}{|c|}{ Control } & \multicolumn{2}{|c|}{ HP inulin } & \multicolumn{2}{|c|}{ Oligofructose } & \multirow[b]{2}{*}{$P$} \\
\hline & Mean & SE & Mean & SE & Mean & SE & \\
\hline \multicolumn{8}{|l|}{$\mathrm{Hb}(\mathrm{g} / \mathrm{l})$} \\
\hline Day 1 & 57 & 0.04 & 54 & 0.02 & 56 & 0.02 & 0.804 \\
\hline Day 7 & 50 & 0.20 & 55 & 0.41 & 53 & 0.33 & 0.785 \\
\hline Day 14 & 57 & 0.22 & 59 & $0 \cdot 16$ & 56 & 0.31 & 0.714 \\
\hline \multicolumn{8}{|l|}{ Haematocrit (\%) } \\
\hline Day 1 & 16 & 0.76 & 16 & 0.86 & 16 & 0.61 & 0.954 \\
\hline Day 7 & 16 & $1 \cdot 31$ & 17 & 1.82 & 17 & 1.66 & 0.41 \\
\hline Day 14 & 16 & $1 \cdot 34$ & 17 & 1.53 & 15 & 1.47 & 0.479 \\
\hline \multicolumn{8}{|l|}{ Body weight (g) } \\
\hline Day 1 & 117 & $4 \cdot 38$ & 119 & 7.9 & 116 & 4.79 & 0.925 \\
\hline Day 7 & 153 & 4.57 & 156 & $9 \cdot 91$ & 150 & $2 \cdot 64$ & 0.953 \\
\hline Day 14 & 192 & $6 \cdot 18$ & 191 & 11.55 & 186 & 4.52 & 0.834 \\
\hline \multicolumn{8}{|l|}{ Body length $(\mathrm{cm})$} \\
\hline Day 1 & 29 & 0.5 & 29 & 0.93 & 29 & 0.43 & 0.695 \\
\hline Day 7 & 31 & 0.54 & 32 & 1.06 & 32 & 0.51 & 0.853 \\
\hline Day 14 & 34 & 0.36 & 35 & $1 \cdot 12$ & 34 & 0.39 & 0.840 \\
\hline Food intake (g) & 161 & $5 \cdot 39$ & 151 & $11 \cdot 28$ & 152 & $6 \cdot 6$ & 0.672 \\
\hline
\end{tabular}

*One-way ANOVA test.

(SE 0.01), $0.47(\operatorname{SE} 0.01)$ and $0.45(\operatorname{SE} 0.01) \mathrm{g} / \mathrm{g}$, respectively $(P=0 \cdot 814)$.

There was no significant difference between the groups in terms of the total intake volume $(\mathrm{ml})$ of deionised water during the dietary treatment period for the control (198.50 (SE 12.55)), HP inulin (210.93 (SE 17.62)) and oligofructose (232.29 (SE 27.61)) groups $(P=0 \cdot 504)$.

\section{Weights of different portions of the intestine and the $\mathrm{pH}$} of caecal contents

There was no significant difference between the groups in relation to the weight of the duodenum or of the proximal colon in rats from the control, HP inulin and oligofructose groups. The weights of the duodenum were 0.6 (SE 0.03), 0.75 (SE 0.04) and 0.77 (SE 0.04) g, respectively $(P>0.05)$, and those of the proximal colon were 0.45 (SE 0.02), 0.51 (SE 0.06) and 0.52 (SE 0.02) g, respectively ( $P>0.05$ ). The weights of the caecum (without content) in the control, HP inulin and oligofructose groups were 0.77 (SE 0.04), 2.1 (SE 0.11) and 1.9 (SE 0.04) g, respectively $(P<0 \cdot 001)$, with a significant difference between the HP inulin and control groups $(P=0 \cdot 001)$, and between the oligofructose and control groups $(P=0 \cdot 001)$. No significant difference was observed between the groups receiving the prebiotics $(P>0.05)$, as revealed by the multiple-comparison Tukey's test. The $\mathrm{pH}$ values of the caecal contents in the control, HP inulin and oligofructose groups were $6 \cdot 14$ (SE 0.14), 5.21 (SE 0.14) and 5.5 (SE 0.46), respectively, with a significant difference between the HP inulin and control groups $(P=0.006)$, and between the oligofructose and control groups $(P=0 \cdot 01)$. No significant difference was observed between the groups receiving the prebiotics $(P>0.05)$.

\section{Intestinal expression of divalent metal transporter 1 ,} ferroportin and duodenal cytochrome b proteins

Western blot analysis revealed no significant $(P>0.05)$ increase in the expression of the proteins DMT1 (Fig. 1), ferroportin (Fig. 2) or Dcytb (Fig. 3), in the duodenal segments of the HP inulin and oligofructose groups. There was a significant increase in the expression levels of the DMT1 protein in the caecum (Fig. 1) of the HP inulin group (increase of $162 \%$ ), compared with that of the control group $(P=0 \cdot 04)$. However, no significant difference was observed between the oligofructose (elevation of $59.4 \%$ ) and control groups ( $P>0.05)$. There was a significant increase in the expression levels of the Dcytb protein (Fig. 3) in the proximal colon segment of the HP inulin group (increase of $135 \%$ ) compared with that of the control group $(P=0 \cdot 02)$. No significant difference was observed between the oligofructose (increase of 23\%) and control groups $(P>0.05)$. There was no significant increase in the expression levels of the ferroportin protein in the duodenum, caecum or proximal colon of the experimental groups (Fig. 2); however, the expression level of this protein was decreased in the oligofructose group $(P=0 \cdot 02)$.

\section{Serum, liver and urinary hepcidin concentrations}

Serum hepcidin concentrations were 87.78 (SE 3.76), 88.31 (SE 2.52 ) and $87.42(\mathrm{se} 7 \cdot 20) \mathrm{pg} / \mathrm{ml}$ in the control, HP inulin and oligofructose groups, respectively. No significant difference was observed between the control, HP inulin and oligofructose groups $(P=0.993)$. The same result was observed for liver hepcidin concentrations between the control, HP inulin and oligofructose groups $(P=0.892)$. Urinary hepcidin concentrations were significantly decreased in the oligofructose group $(P<0 \cdot 001)$ compared with that of the control 
Fig. 1. Protein expression levels of divalent metal transporter 1 (DMT1) in the duodenum, caecum and proximal colon of anaemic rats from the control ( $\square$ ), HP inulin $(\square)$ and oligofructose $(\square)$ groups. Protein levels were determined by Western blot analysis and normalised to the levels of $\alpha$-tubulin. Values are means $(n 4-7$ per group), with their standard errors represented by vertical bars. ${ }^{a, b}$ Mean values with unlike letters were significantly different $(P=0.04)$. a.u., Arbitrary units.

group (Table 3). However, no significant difference was observed between the HP inulin and control groups $(P>0 \cdot 05)$.

\section{IL-10, IL-6 and TNF- $\alpha$ concentrations in the caecum,} proximal colon and liver

Oligofructose decreased the levels of IL-10 ( $P=0 \cdot 044)$, IL-6 $(P=0.036)$ and TNF- $\alpha(P=0.004)$ in the caecum (Table 4). No significant difference was observed between the HP inulin and control groups $(P>0.05)$. No changes were observed in the levels of IL-10, IL- 6 or TNF- $\alpha$ in the liver or proximal colon of the HP inulin and oligofructose groups.

\section{Discussion}

The present study showed that HP inulin increased the expression levels of DMT1 in the caecum and of Dcytb in the colon. Oligofructose did not induce differences in these proteins compared with the control group. However, oligofructose decreased urinary hepcidin concentrations, and also decreased the expression of the ferroportin protein in the duodenum, and decreased the levels of TNF- $\alpha$, IL- 6 and IL-10 in the caecum.

Therefore, in the present study, it is clear that HP inulin and oligofructose exerted promotive effects via different

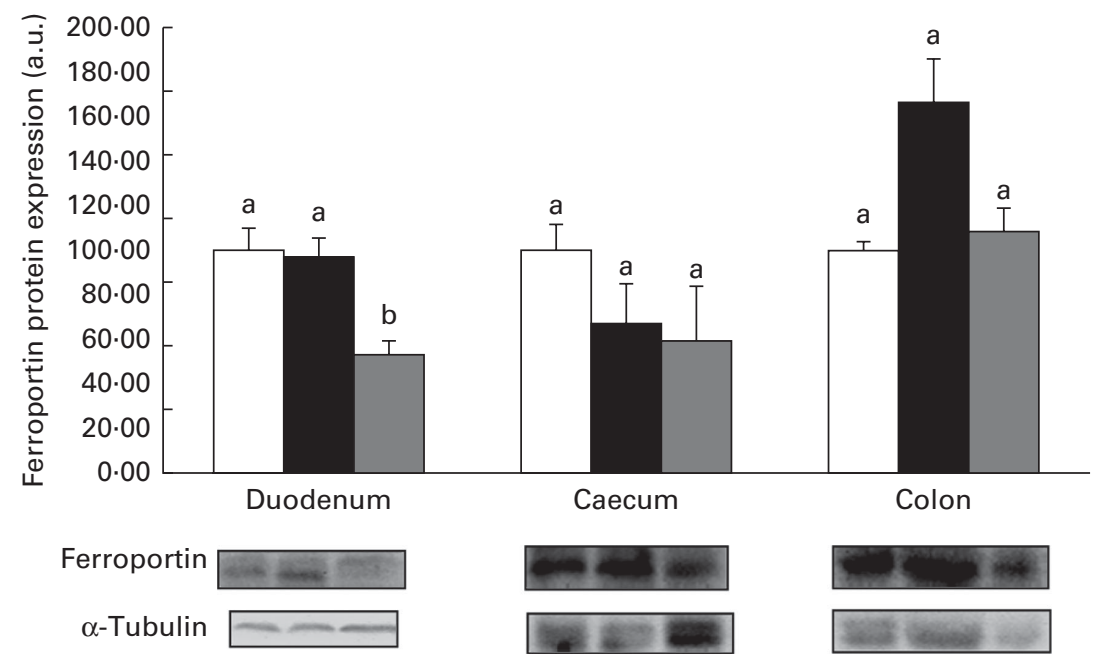

Fig. 2. Protein expression levels of ferroportin in the duodenum, caecum and proximal colon of anaemic rats from the control ( $\square$ ), HP inulin ( $\square$ ) and oligofructose $(\square)$ groups. Protein levels were determined by Western blot analysis and normalised to the levels of $\alpha$-tubulin. Values are means ( $n$ 5-7 per group), with their standard errors represented by vertical bars. ${ }^{a, b}$ Mean values with unlike letters were significantly different $(P=0.02)$. a.u., Arbitrary units. 


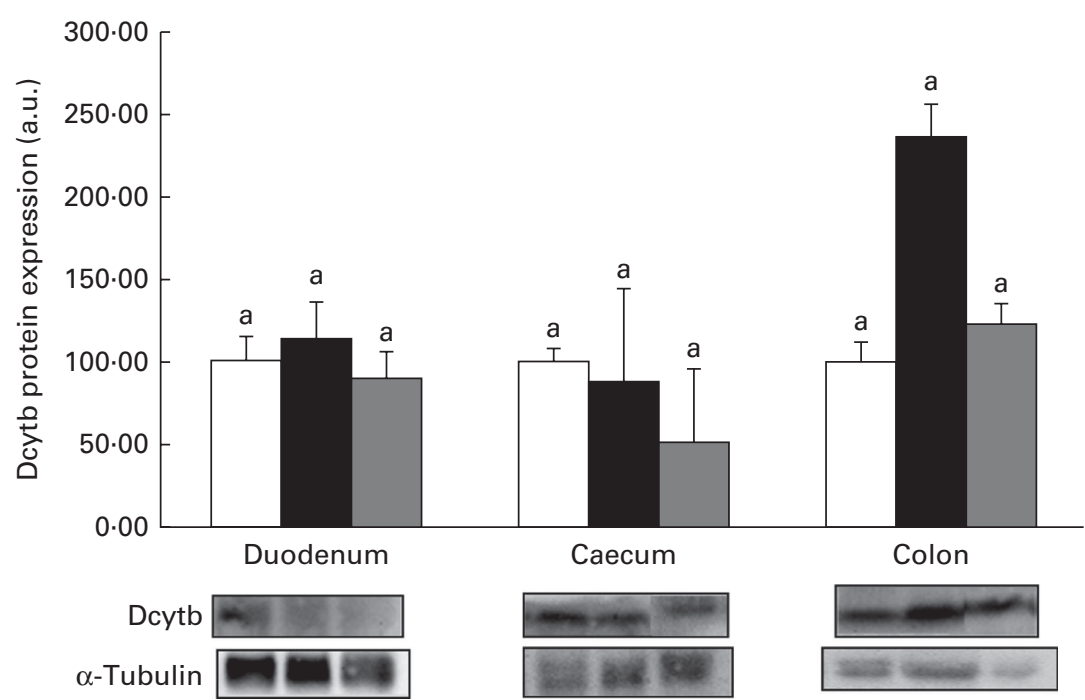

Fig. 3. Protein expression levels of duodenal cytochrome b (Dcytb) reductase in the duodenum, caecum and proximal colon of anaemic rats from the control ( $\square$ ), HP inulin ( $\square$ ) and oligofructose ( $\square$ ) groups. Protein levels were determined by Western blot analysis and normalised to the levels of $\alpha$-tubulin. Values are means $(n 5-7$ per group), with their standard errors represented by vertical bars. ${ }^{\mathrm{a}, \mathrm{b}}$ Mean values with unlike letters were significantly different $(P=0.02)$. a.u., Arbitrary units.

mechanisms. Rossi et al. ${ }^{(23)}$ observed that in faecal cultures, oligofructose and inulin strongly affected the products of fermentation. Different types and amounts of SCFA were produced. During the growth phase, inulin produced butyrate, the major fermentation product, whereas oligofructose produced acetate and lactate. These findings reflect the consequence of the different effects of oligofructose and inulin on microflora composition and activity. The rate of fermentative metabolism is faster on oligofructose than on inulin. However, both oligofructose and inulin demonstrate clear prebiotic effects, but differences occur in fermentation kinetics because of the different degrees of polymerisation ${ }^{(24)}$. These different degrees of polymerisation distribution affect the kinetics of microbial changes and activities, and result in a faster production of butyric acid on inulin than on oligofructose. The increase in the concentrations of Lactobacillus and Bifidobacterium occurs earlier on oligofructose than on inulin. The short chains of oligofructose are more easily metabolised by Bifidobacterium than are the longer chains of inulin ${ }^{(23)}$.

These differences may partially explain the increase observed in the expression levels of DMT1 in the caecum and of Dcytb in the colon by inulin, but not by oligofructose, consistent with the study of Pompei et al. ${ }^{(24)}$. Inulin is a long-chain fructan with a degree of polymerisation ranging from 2 to 60 units, and an average degree of polymerisation of 10-12 units. Therefore, inulin is degraded slowly, and can exert its effects on the distal regions of the large intestine $^{(25)}$. However, because oligofructose has an average degree of polymerisation of 4 units, it is degraded faster and can affect the proximal regions ${ }^{(26)}$.

Yasuda et al.$^{(14)}$ observed that inulin and oligofructose have greater effects on the caecum and colon compared with the duodenum, and their metabolites influence gene expression levels in the caecum and colon. They also claimed that inulin and oligofructose show similar effects on genes involved in the regulation of $\mathrm{Fe}$ metabolism, regardless of the chain length, which implies a similar mode of action. In contrast, the present study indicated no increase in the expression levels of DMT1, ferroportin and Dcytb in the large intestine, following oligofructose treatment. The only change observed in the present study following the treatment with oligofructose was the reduction in the expression levels of ferroportin in the duodenum.

DMT1 is expressed in both rat duodenum and colon. In keeping with their expected roles in body Fe metabolism, DMT1 protein levels in the duodenum greatly exceed those in colonic tissue. However, despite these differential expression levels, the DMT1 protein is up-regulated in the

Table 3. Hepcidin levels in the serum, liver and urine of anaemic rats from the control, high-performance (HP) inulin and oligofructose groups (Mean values with their standard errors)

\begin{tabular}{|c|c|c|c|c|c|c|}
\hline & \multicolumn{2}{|c|}{ Control } & \multicolumn{2}{|c|}{ HP inulin } & \multicolumn{2}{|c|}{ Oligofructose } \\
\hline & Mean & SE & Mean & SE & Mean & SE \\
\hline Serum hepcidin (pg/ml) & $87 \cdot 78^{\mathrm{a}}$ & 3.76 & $88 \cdot 31^{\mathrm{a}}$ & $2 \cdot 52$ & $87.42^{\mathrm{a}}$ & $7 \cdot 20$ \\
\hline Liver hepcidin $(\mathrm{pg} / \mathrm{mg})$ & $3.69^{\mathrm{a}}$ & 0.28 & $3.91^{\mathrm{a}}$ & 0.40 & $3 \cdot 70^{\mathrm{a}}$ & 0.26 \\
\hline Urinary hepcidin (pg/ml) & $2.42^{\mathrm{a}}$ & 0.14 & $2 \cdot 31^{\mathrm{a}}$ & 0.23 & $0.96^{\mathrm{b}}$ & 0.18 \\
\hline
\end{tabular}

${ }^{a, b}$ Means values within a row with unlike superscript letters were significantly different $(P<0.001$ one-way ANOVA). 
Table 4. IL-10, IL-6 and TNF- $\alpha$ concentration for caecum, proximal colon and liver in animals of the control, high-performance (HP) inulin and oligofructose groups (Mean values with their standard errors)

\begin{tabular}{|c|c|c|c|c|c|c|}
\hline \multirow[b]{2}{*}{ Variables $(\mathrm{pg} / \mu \mathrm{g})$} & \multicolumn{2}{|c|}{ Control } & \multicolumn{2}{|c|}{ HP inulin } & \multicolumn{2}{|c|}{ Oligofructose } \\
\hline & Mean & SE & Mean & SE & Mean & SE \\
\hline \multicolumn{7}{|l|}{ Caecum } \\
\hline IL-10 & $8.27^{\mathrm{a}}$ & 0.79 & $7.86^{a}$ & $2 \cdot 60$ & $2 \cdot 74^{\mathrm{b}}$ & 0.75 \\
\hline IL-6 & $56 \cdot 57^{\mathrm{a}}$ & 7.48 & $80 \cdot 33^{a}$ & $12 \cdot 26$ & $25 \cdot 40^{\mathrm{b}}$ & $10 \cdot 41$ \\
\hline TNF- $\alpha$ & $8 \cdot 32^{\mathrm{a}}$ & 1.14 & $9 \cdot 81^{a}$ & 0.72 & $3.43^{\mathrm{b}}$ & 0.90 \\
\hline \multicolumn{7}{|l|}{ Proximal colon } \\
\hline IL-10 & $11 \cdot 97^{\mathrm{a}}$ & $4 \cdot 14$ & $14 \cdot 90^{\mathrm{a}}$ & 4.56 & $8.07^{\mathrm{a}}$ & 2.03 \\
\hline IL-6 & $71 \cdot 22^{\mathrm{a}}$ & $15 \cdot 36$ & $101 \cdot 25^{a}$ & 23.52 & $49.95^{a}$ & 17.97 \\
\hline TNF- $\alpha$ & $8.32^{a}$ & 2.02 & $10 \cdot 35^{a}$ & 1.67 & $4.75^{\mathrm{a}}$ & 1.90 \\
\hline \multicolumn{7}{|l|}{ Liver } \\
\hline $\mathrm{IL}-10$ & $30 \cdot 13^{a}$ & $7 \cdot 73$ & $35 \cdot 34^{\mathrm{a}}$ & 8.36 & $33.37^{a}$ & 7.45 \\
\hline IL-6 & $123 \cdot 82^{a}$ & 35.62 & $135 \cdot 42^{\mathrm{a}}$ & 29.53 & $162 \cdot 36^{a}$ & 32.74 \\
\hline TNF- $\alpha$ & $9.55^{a}$ & 2.50 & $12 \cdot 86^{a}$ & 3.50 & $10 \cdot 88^{a}$ & $3 \cdot 16$ \\
\hline
\end{tabular}

${ }^{a, b}$ Means values within a row with unlike superscript letters were significantly different in comparison between groups ( $P \leq 0.05$; one-way ANOVA test).

colon of Fe-deficient rats compared with control Fe diet-fed rats, exhibiting an increase of $147 \%{ }^{(27)}$. Thus, the anaemic group that did not receive the prebiotics was the control group because anaemia is an adaptive mechanism in which increased expression levels of genes that regulate Fe absorption are observed in the duodenum, caecum and colon ${ }^{(4,27)}$. These anaemic animals have also been used as controls in similar studies $^{(9,14)}$

In the present study, the expression level of the DMT1 protein in the caecum was significantly higher in the HP inulin group than in the control group, exhibiting an increase of $162 \%$. Similarly, Tako et $a l^{(9)}$ observed an increase in DMT1 gene expression levels in the colon (120\%) compared with the control group. Consistent with the latter study, HP inulin in the present study increased the expression levels of the Dcytb protein in the colon by $135 \%$, but the increase was $70 \%$ in Tako et al. ${ }^{(9)}$. The almost 2 -fold increase observed in the present study may be attributed to the use of more than twice the concentration of inulin in the diet, when compared with the diet in Tako et al. ${ }^{(9)}$. HP inulin did not alter the expression levels of proteins that regulate $\mathrm{Fe}$ absorption in the duodenum. However, Tako et $a{ }^{(9)}$ found increased gene expression levels of these factors in the duodenum.

HP inulin and oligofructose did not alter the hepatic or serum concentration of hepcidin in the present study. Our hypothesis was that there was a decrease in the levels of hepcidin in the serum and liver tissue. However, oligofructose reduced the urinary concentration of hepcidin, which was accompanied by a reduction in ferroportin protein expression levels in the duodenum. The hepcidin-ferroportin axis is the principal regulator of extracellular $\mathrm{Fe}$ homeostasis in health and disease. In the present study, these results suggest an increase in the formation of the ferroportin-hepcidin complex, in which ferroportin is internalised and degraded in lysosomes ${ }^{(3)}$. Therefore, it is questionable whether this pattern could reduce the absorption of $\mathrm{Fe}$ and increase anaemia, because it reduces $\mathrm{Fe}$ that is available in the plasma. However, Tako et al. ${ }^{(9)}$ and Yasuda et al. ${ }^{(14)}$ reported that oligofructose increases ferritin expression, which suggests increased Fe stores and the existence of a negative feedback loop to decrease Fe absorption. Nevertheless, Freitas et al. ${ }^{(13)}$ observed that oligofructose increased Fe absorption in growing anaemic rats. More studies are needed to clarify the effects of oligofructose on the homeostasis of Fe absorption and on hepcidin levels in the serum and urine.

Pro-inflammatory TNF- $\alpha$ and IL-6, and anti-inflammatory IL-10 increase ferritin protein expression levels, and IL-10 and IL-6 increase the acquisition of $\mathrm{Hb}$ by macrophages, which also increases Fe uptake ${ }^{(15)}$. Oligofructose reduced the concentrations of IL-6, TNF- $\alpha$ and IL-10 in the caecum in the present study, which suggests that oligofructose used other mechanisms of action to make Fe available to the plasma. These results corroborate those of Freitas et al. ${ }^{(13)}$ who observed that oligofructose significantly increased $\mathrm{Hb}$ recovery in growing anaemic rats. This observation is important to the study of Fe-deficiency anaemia because these IL contribute to hypoferraemia, reduce $\mathrm{Hb}$ and impair erythropoiesis ${ }^{(28)}$. The low concentration of TNF- $\alpha$ in the caecum could reduce ferritin and promote the availability of $\mathrm{Fe}$ for $\mathrm{Hb}$ regeneration ${ }^{(15,29)}$. Yasuda et al. ${ }^{(14)}$ demonstrated a reduction in the expression levels of the $T N F-\alpha$ gene in the colon of anaemic pigs fed inulin and oligofructose. They also reported that the final concentrations of $\mathrm{Hb}$ and haematocrit in these pigs were higher than those of the control group after 7 weeks of feeding, and this was possible even without Fe supplementation. The present study focused on Fe-deficiency anaemia instead of inflammation anaemia, but many infectious and immunosuppressive diseases cause Fe-deficiency anaemia, which suggests changes in inflammatory patterns ${ }^{(14)}$. Therefore, further studies are needed to clarify the role of these prebiotics on IL in Fe-deficiency anaemia, considering the pleiotropic effects of IL, that may aggravate anaemia.

There were no changes in the weight, growth or food intake between the experimental groups in the present study. However, the prebiotic groups showed significant increases in caecal weight and decreases in luminal $\mathrm{pH}$ after euthanasia, which indicates a prebiotic effect of the experimental diets. 
Therefore, HP inulin and oligofructose may affect the expression levels of proteins that regulate Fe absorption in the large intestine. Importantly, the present study was the first to evaluate the effects of prebiotics on hepcidin concentrations in the serum, liver and urine. Hepcidin is an important hormone involved in the regulation of systemic Fe metabolism. Further studies elucidating the action of prebiotics on intestinal $\mathrm{Fe}$ absorption and systemic regulatory mechanisms in Fe-deficiency anaemia should be conducted. These studies should investigate hepcidin and IL signalling pathways, which are widely studied in relation to inflammatory anaemia, but seldom investigated in the context of Fe-deficiency anaemia.

\section{Acknowledgements}

The authors thank the staff of the Physiology of Nutrition Discipline wing of the Department of Physiology, Federal University of São Paulo.

The present study was supported by the National Council of Technological and Scientific Development - CNPq, Brazil (grant no. 2010-1/303791). The funder had no role in the design and analysis of the study or in the writing of this article.

The authors' contributions are as follows: R. M., L. M. O. and M. B. d. M. contributed to the project design, data analysis, statistical analysis, final revision and submission of the manuscript; R. M. conducted the animal experiments; R. M., A. B. S., A. A. d. S., M. d. L. C. S., O. M. S. A. and L. M. O. performed the laboratory analyses; R. M., L. M. O., C. M. d. P. O. d. N. and M. B. M. contributed to the critical revision of the manuscript for important intellectual content.

The authors declare that there are no conflicts of interest.

\section{References}

1. McLean E, Cogswell M, Egli I, et al. (2009) Worldwide prevalence of anaemia, WHO Vitamin and Mineral Nutrition Information System, 1993-2005. Public Health Nutr 12, 444-454.

2. Frazer DM, Wilkins SJ, Becker EM, et al. (2002) Hepcidin expression inversely correlates with the expression of duodenal iron transporters and iron absorption in rats. Gastroenterology 123, 835-844.

3. Ganz T (2011) Hepcidin and iron regulation, 10 years later. Blood 117, 4425-4433.

4. Takeuchi EN, Bjarnason I, Laftah AH, et al. (2005) Expression of iron absorption genes in mouse large intestine. Scand J Gastroenterol 40, 169-177.

5. Nemeth E, Tuttle MS, Powelson J, et al. (2004) Hepcidin regulates cellular iron efflux by binding to ferroportin and inducing its internalization. Science 306, 2090-2093.

6. Anderson GJ, Frazer DM, Wilkins SJ, et al. (2002) Relationship between intestinal iron-transporter expression, hepatic hepcidin levels and the control of iron absorption. Biochem Soc Trans 30, 724-726.

7. Ganz T (2004) Hepcidin in iron metabolism. Curr Opin Hematol 11, 251-254.

8. Roberfroid MB (2007) Inulin-type fructans: functional food ingredients. J Nutr 137, 2493-2502.

9. Tako E, Glahn RP, Welch RM, et al. (2008) Dietary inulin affects the expression of intestinal enterocyte iron transporters, receptors and storage protein and alters the microbiota in the pig intestine. Br J Nutr 99, 472-480.
10. Roberfroid MB (2005) Introducing inulin-type fructans. $\mathrm{Br} J$ Nutr 93, 13-25.

11. Ohta A, Ohtsuki M, Baba S, et al. (1995) Effects of fructooligosaccharides on the absorption of iron, calcium and magnesium in iron-deficient anemic rats. J Nutr Sci Vitaminol 41, 281-291.

12. Lopez HW, Coudray C, Levrat-Verny M, et al. (2000) Fructooligosaccharides enhance mineral apparent absorption and counteract the deleterious effects of phytic acid on mineral homeostasis in rats. J Nutr Biochem 11, 500-508.

13. Freitas KC, Amancio OM \& Morais MB (2012) Highperformance inulin and oligofructose prebiotics increase the intestinal absorption of iron in rats with iron deficiency anaemia during the growth phase. Br J Nutr 108, 1008-1016.

14. Yasuda K, Dawson HD, Wasmuth EV, et al. (2009) Supplemental dietary inulin influences expression of iron and inflammation related genes in young pigs. J Nutr 139, 2018-2023.

15. Koorts AM, Levay PF, Becker PJ, et al. (2011) Pro- and anti-inflammatory cytokines during immune stimulation: modulation of iron status and red blood cell profile. Mediators Inflamm 2011, 1-11.

16. Reeves PG, Nielsen FH \& Fahey GC (1993) AIN-93 purified diets for laboratory rodents: final report of the American Institute of Nutrition ad boc writing committee on the reformulation of the AIN-76A rodent diet. J Nutr 123, 1939-1951.

17. Borel MJ, Smith SH, Brigham DE, et al. (1991) The impact of varying degrees of iron nutriture on several functional consequences of iron deficiency in rats. $J$ Nutr 121, 729-736.

18. Dirks P \& Freeman HJ (1987) Effects of differing purified cellulose, pectin and hemicellulose fiber diets on mucosal morphology in the rat small and large intestine. Clin Invest Med 10, 32-38.

19. Younes H, Coudray C, Bellanger J, et al. (2001) Effects of two fermentable carbohydrates (inulin and resistant starch) and their combination on calcium and magnesium balance in rats. Br J Nutr 86, 479-485.

20. Lopez HW, Levrat-Verny M, Coudray C, et al. (2001) Class 2 resistant starches lower plasma and liver lipids and improve mineral retention in rats. $J$ Nutr 131, 1283-1289.

21. Wintrobe M, Mollin D, Herbert V, et al. (1968) Anemias nutricionales. Org Mund Salud Ser Inf Técn 405, 5-39.

22. Rosa Neto JC, Lira FS, Oyama LM, et al. (2009) Exhaustive exercise causes an anti-inflammatory effect in skeletal muscle and a pro-inflammatory effect in adipose tissue in rats. Eur J Appl Physiol 106, 697-704.

23. Rossi M, Corradini C, Amaretti A, et al. (2005) Fermentation of fructooligosaccharides and inulin by bifidobacteria: a comparative study of pure and fecal cultures. Appl Environ Microbiol 71, 6150-6158.

24. Pompei A, Cordisco L, Raimondi S, et al. (2008) In vitro comparison of the prebiotic effects of two inulin-type fructans. Anaerobe 14, 280-286.

25. Wiele TV, Boon N, Possemiers S, et al. (2006) Inulin-type fructans of longer degree of polymerization exert more pronounced in vitro prebiotic effects. J Appl Microbiol 102, 452-460.

26. Roberfroid MB, Van Loo JAE \& Gibson GR (1998) The bifidogenic nature of chicory inulin and its hydrolysis products. J Nutr 128, 11-19.

27. Johnston KL, Johnson DM, Marks J, et al. (2006) Non-haem iron transport in the rat proximal colon. Eur J Clin Invest 36, 35-40.

28. Grotto HZW (2008) Metabolismo do ferro: uma revisão sobre os principais mecanismos envolvidos em sua homeostase (Iron metabolism: an overview of the main mechanisms involved in its homeostasis). Rev Bras Hematol Hemoter 30, 390-397.

29. Torti FM \& Torti SV (2002) Regulation of ferritin genes and protein. Blood 99, 3505-3516. 